\title{
Treatment of horizontal root-fractured maxillary incisors
}

\author{
Sung-Hyeon Choi ${ }^{\dagger}$, Ji-Hye Yoon ${ }^{\dagger}$, Bin-Na Lee, Hoon-Sang Chang, In-Nam Hwang, Won-Mann Oh, Yun-Chan Hwang*
}

Department of Conservative Dentistry, Dental Science Research Institute, School of Dentistry, Chonnam National University, Gwangju, Korea

\begin{abstract}
Root fractures are defined as fractures that involve the dentin, cementum, and pulp, resulting in stretching or laceration of the pulp and/or periodontal ligament injury (rupture or compression). Two cases of horizontal root-fractured maxillary incisors are introduced in the present report. The first case is a middle third root-fractured maxillary incisor with root canal therapy in the coronal fragment, and the second case is a cervical third root-fractured maxillary incisor without root canal therapy. Both cases showed favorable results with a long-term follow-up period. In all traumatic injuries, early diagnosis and appropriate intervention dramatically enhance the outcome. The primary purpose of the treatment of root-fractured teeth is to maintain the vitality of the teeth. After an adequate observation period, if vitality control reveals non-vital pulp tissue, or if the patient complains of pain or discomfort in the tooth, endodontic therapy can be performed, usually to the coronal segment only.
\end{abstract}

Key Words: Emergency, Injury, Root canal therapy, Tooth fracture, Trauma

@) This is an open-access article distributed under the terms of the Creative Commons Attribution Non-Commercial License (http://creativecommons.org/licenses/by-nc/4.0) which permits unrestricted noncommercial use, distribution, and reproduction in any medium, provided the original work is properly cited.

\section{INTRODUCTION}

Most dental trauma occurs in the 7- to 12-year-old age group and is mainly due to falls and accidents near home or school $[1,2]$. It occurs primarily in the anterior region of the mouth, affecting the maxillary more than the mandibular jaw [3]. Serious accidents like traffic crashes can affect any tooth and occur in all age ranges. In many cases, after a traumatic dental injury, endodontic therapy is provided to caries-free, single-rooted, young permanent teeth. If quick and correct treatment for these teeth is provided after injury, the potential for a successful endodontic outcome is very good.
Root fractures are defined as fractures that involve dentin, cementum and the pulp, resulting in stretching or laceration of the pulp and/or periodontal ligament injury (rupture or compression) [4]. Root fractures are relatively rare trauma, comprising from $0.5 \%$ to $7.0 \%$ of injuries in permanent dentition [5]. Immature teeth with vital pulps rarely sustain horizontal root fractures [6]. Horizontal root fractures commonly occur at the anterior maxilla and teeth with complete root formation. When horizontal root fractures occur, the apical fragment generally shows no displacement while the coronal fragment shows various displacement. Because the apical pulpal circulation is not disrupted, pulp necrosis in the apical segment is extremely

Received July 8, 2019; Revised September 5, 2019; Accepted September 5, 2019

Corresponding author: Yun-Chan Hwang, Department of Conservative Dentistry, School of Dentistry, Chonnam National University, 77 Youngbong-ro, Buk-gu, Gwangju 61186, Korea.

Tel: +82-62-530-5831, Fax: +82-62-530-5629, E-mail: ychwang@chonnam.ac.kr

${ }^{\dagger}$ These authors contributed equally to this work.

Copyright $\odot$ 2019, Oral Biology Research Institute 
rare. Permanent pulpal necrosis of the coronal segment, requiring endodontic treatment, occurs in about $25.0 \%$ of cases [7-9]. According to the International Association of Dental Traumatology (IADT) guidelines, if displaced, the coronal segment of the tooth is repositioned as soon as possible and stabilized with a flexible splint for 4 weeks [10]. If the root fracture is near the cervical area of the tooth, stabilization is beneficial for a longer period of time (up to 4 months). It is advisable to monitor healing for at least 1 year to determine pulpal status. In 1967, Andreasen and Hjorting-Hansen [11] found that the necrosis of the pulp usually occurs only in the coronal fragment, while the pulp of the apical fragment remains vital. If pulp necrosis develops, root canal treatment of the coronal tooth segment to the fracture line is indicated to preserve the tooth.

The healing process of horizontal fractures depends on variable factors such as age, fracture type, location of fracture, severity of dislocation, treatment delay, splinting type, and period etc. [12].

This case report describes the clinical management and different healing types in 2 cases of horizontal root frac- tures in maxillary central incisors.

\section{CASE}

\section{Case 1}

A 14-year-old male patient was fell down from the bicycle and suffered an injury in the upper anterior teeth with laceration of mucosa of the upper lip. The patient visited the emergency center, Department of Oral Maxillofacial Surgery at Chonnam National University Hospital (CNUH OMS), immediately after the trauma. According to the record, the left upper central incisor (\#21) was avulsed and right upper central incisor (\#11) was horizontally root fractured (Fig. 1A). The patient brought the \#21 tooth in a cup of milk. Rigid splinting with arch bar and semi-rigid splinting with resin wire splinting were performed. After 3 weeks, the patient was referred from the CNUH OMS to the Department of Conservative Dentistry at Chonnam National University Dental Hospital (CNUDH CONS). Clinically, the resin wire splint was removed and arch bar
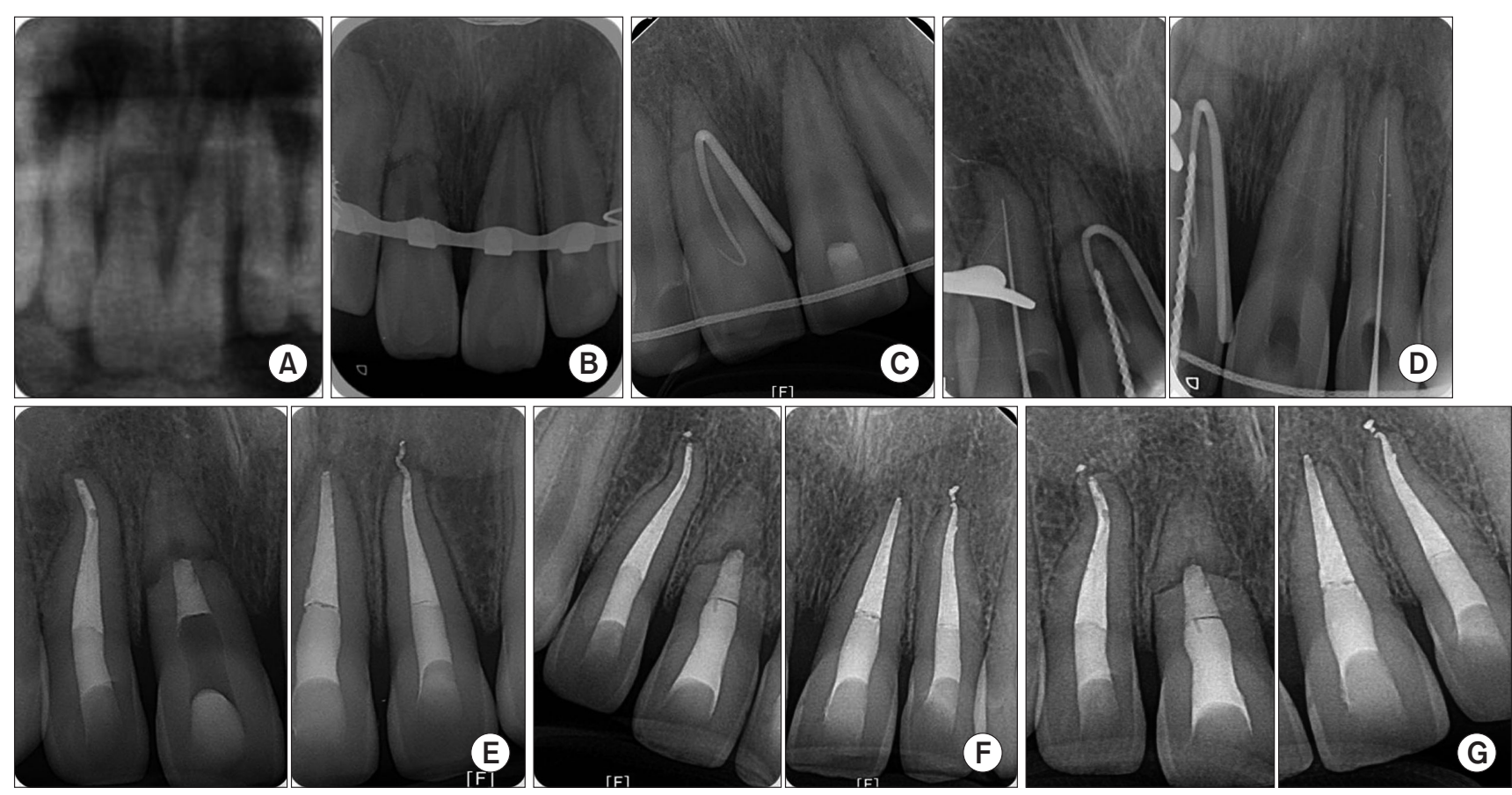

Fig. 1. (A) The maxillary right central incisor (\#11) was horizontally root fractured. (B) Initial periapical radiograph when the patient visited to Department of Conservative Dentistry at Chonnam National University Dental Hospital. (C) After 3 weeks of re-reduction due to secondary trauma, sinus tract occurred on \#11 buccal gingival area and gutta percha tracing was performed. (D) Working length determination of traumatized teeth. (E) Postoperative periapical radiograph. (F) 4-month follow-up radiograph. (G) 12-month follow-up radiograph. 
was left on maxillary area (Fig. 1B). Intraoral examination revealed intense percussion sensibility in the $\# 11, \# 21$, \#22 teeth, mobility in the \#11, \#21 teeth, no response to both electric pulp test and cold test in the \#11, \#21, \#22 teeth, but no color alteration in all teeth. \#11 tooth was palatally dislocated. In radiographic examination, horizontal root fracture on the middle-third of the \#11 tooth was clearly visible. All anterior maxillary teeth presented complete radicular development, including the traumatized tooth, and no bone alterations were noted. Additionally, the left upper lateral incisor (\#22) and the right upper lateral incisor (\#12) showed periapical radiolucency, suggesting extrusive luxation. We carried out a semi-rigid fixation to the buccal surface of the maxillary anterior teeth using composite resin and wire. Access opening was performed in the $\# 21$ tooth. Calcium hydroxide as an intracanal medicament was applied for 1 month and maintained until the definitive canal filling by lateral condensation technique with gutta-percha points and AH Plus sealer (Dentsply DeTrey, Konstanz, Germany). However, after 4 days after the treatment, the patient suffered a trauma again. Both clinical and radiographic examination showed a lot more dislocation of \#11 and \#21 teeth, especially a diastasis greater than 1 $\mathrm{mm}$ in the fracture line on \#11 tooth. Semi-rigid resin wire splinting was performed again (Fig. 2B). In 3 weeks after the re-reduction treatment, sinus tract on buccal gingiva in the \#11 area was observed. Necrosis of pulp in the coronal fragment of \#11 tooth was identified using cold test, electronic pulp test (EPT) and gutta-percha cone tracing (Fig.
1C). Endodontic treatment of the coronal fragment was initiated. Working length was estimated using electronic apex locator (DentaPort Root ZX; J Morita USA, Irvine, CA, USA) and confirmed using a periapical radiograph. All the canals were cleaned and shaped using ProTaper NiTi rotary instruments (ProTaper Next; Dentsply-Maillefer, Ballaigues, Switzerland) with a crown-down technique and endodontic K-files (M access; Dentsply-Maillerfer) (Fig. 1D). Copious irrigation was performed using a 5.25\% sodium hypochlorite $(\mathrm{NaOCl})$ solution and sterile saline using ultrasonic irrigation tip (Irrisafe; Acteon Satelec, GmbH, Germany) according to the manufacturer's instructions. The canals were dried with paper points and calcium hydroxide was applied for 1 month. At the following visit, the sinus tract was disappeared and the coronal fragment was filled with mineral trioxide aggregate (ProRoot MTA; Dentsply International Inc., Johnson City, TN, USA) as apical plug. Coronal restorations were performed using composite resin at the following visit. The \#12 and \#22 teeth showed lasting negative response to pulp sensibility tests, so the root canal therapy was also conducted as well. Necrosis of pulp of both teeth was identified in access opening procedure. Calcium hydroxide dressing was performed for 1 month and maintained until the definitive canal filling by lateral condensation technique with gutta-percha points and $\mathrm{AH}$ Plus (Fig. 1E). In the 12-month follow-up, radiographs showed healing between the root fragments and radiolucency had decreased in the fracture line (Fig. 1G).
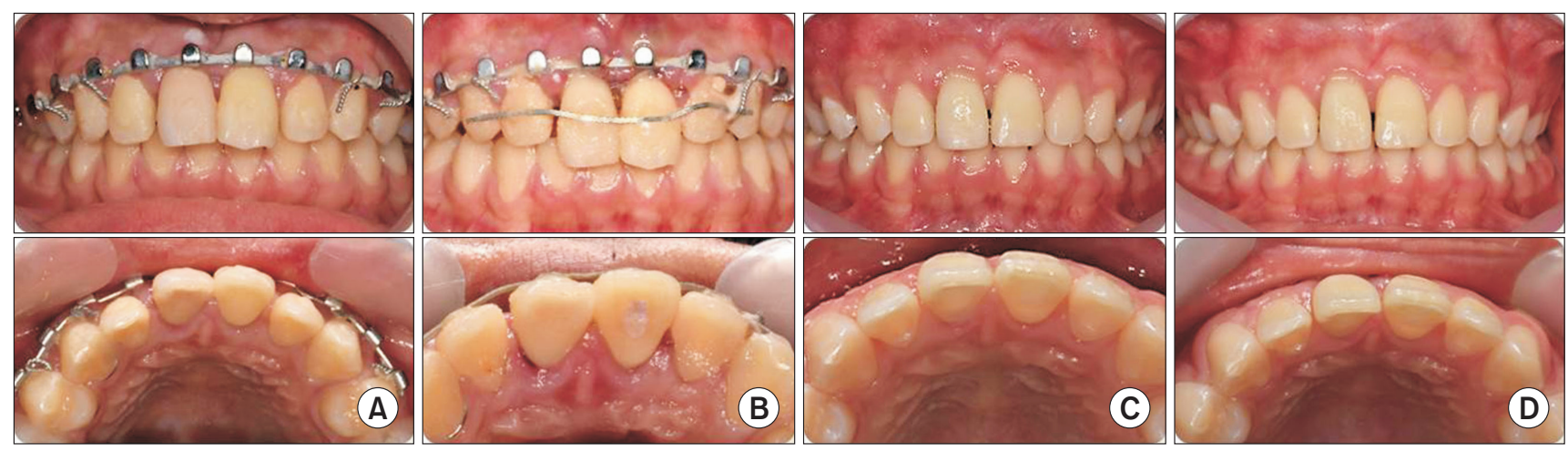

Fig. 2. (A) Preoperative clinical photograph when the patient visited to Department of Conservative Dentistry at Chonnam National University Dental Hospital. (B) Clinical photograph after semi-rigid resin wire splinting was performed again after secondary trauma occurred. (C) Postoperative clinical photograph. (D) 4-month follow-up clinical photograph. 
Case 2

A 17-year-old female patient suffered an injury in the upper anterior teeth and visited the CNUDH CONS. The intraoral examination revealed a slight mobility, intense percussion sensitivity, negative response to pulp sensibility test (electric pulp test, cold test) in the left upper central incisor (\#21). However, no displacement of the coronal fragment, no symptoms were observed. Radiographic examination showed a horizontal root fracture in the cervical third of tooth \#21 (Fig. 3A). It was also observed that all the apices of the upper anterior teeth were completely formed.

Semi-rigid resin wire splinting was performed and follow-up evaluation was planned (Fig. 3B). For 1 month, the patient visited the clinic every week and the pulp sensibility test was performed. Electric pulp test of \#21 tooth showed delayed positive response 1 month after the trauma and no discoloration was observed. Resin wire splint was removed after 2 month of fixation. Mobility of \#21 tooth was decreased compared to the initial mobility but we decided to splint \#11, 21, 22 teeth using composite resin for more 2 months (total 4 months of splinting) according to the IADT guideline. In the 8.6-year follow-up (Fig. 3F, 4C, D), \#21 tooth showed no symptoms, no discoloration, no mobility and the both electrical pulp test and cold test showed positive response. Radiographs also showed evident healing between the root fragments without periapical radiolucency.

\section{DISCUSSION}

In 1967, Andreasen and Hjorting-Hansen [11] classified root fracture healing into four groups: (1) healing with calcified tissue. Radiographically, the fracture line is discernible, but the fragments are in close contact. (2) Healing with interproximal connective tissue. Radiographically, the fragments appear separated by a narrow radiolucent line, and the fractured edges appear rounded. (3) Healing with interproximal bone and connective tissue. Radiographically, the fragments are separated by as distinct bony ridge. (4) Interproximal inflammatory tissue without healing. Radiographically, a widening of the fracture line and/or a developing radiolucency corresponding to the fracture line becomes apparent. In their retrospective study in 2004 [13], 170 teeth out of 400 teeth (43.0\%) had healed by interposition of periodontal ligament alone, 120 teeth $(30.0 \%)$ had
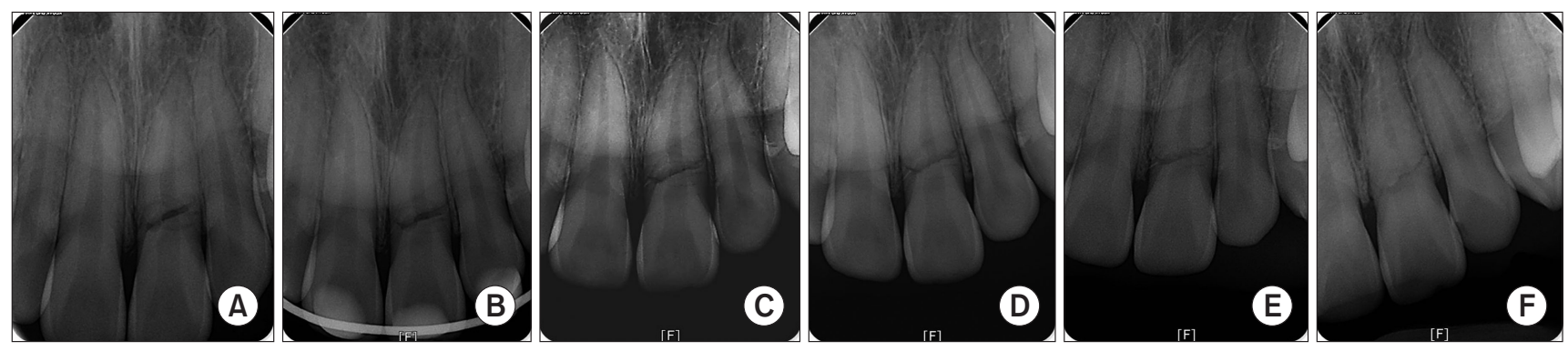

Fig. 3. (A) Preoperative periapical radiograph of the maxillary left central incisor (\#21). Radiographic examination showed a horizontal root fracture in the cervical $1 / 3$ of tooth \#21. (B) Semi-rigid resin wire splinting was performed. (C) 6-month follow-up radiograph. (D) 10-month follow-up radiograph. (E) 16-month follow-up radiograph. (F) 8.6-year follow-up radiograph.
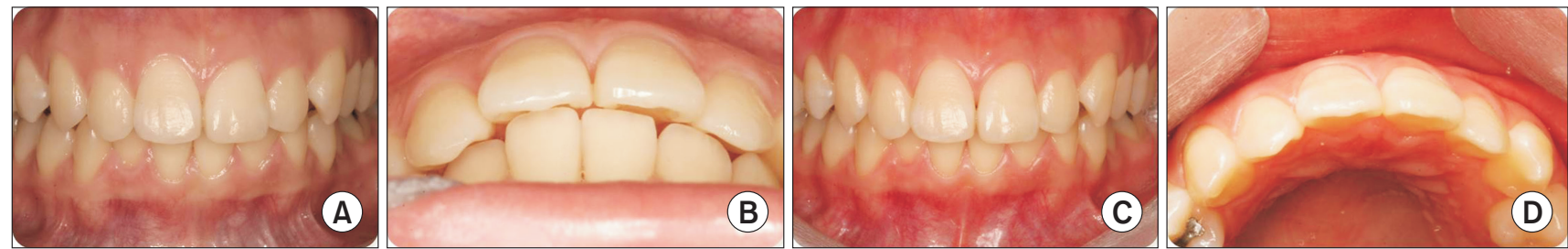

Fig. 4. (A) 16-month follow-up clinical photograph. (B) Interocclusion relationship when 16-month follow-up. (C) 8.6-year follow-up clinical photograph. No crown discoloration is observed. (D) 8.6-year follow-up clinical photograph (occlusal view). 
healed by hard tissue fusion of the fragments and the interposition of periodontal ligament and bone between fragments was found in 22 teeth (5.5\%). Non-healing with pulp necrosis and inflammatory changes between fragments, was seen in 88 teeth (22.0\%).

There are several factors that affects the healing patterns including preinjury factors, injury factors, and treatment factors [14]. Injury factors are the factors directly affects pulp injury which includes fragment mobility, fragment dislocation, and radiographic diastasis. The larger dislocation and mobility leads to lower chance of pulp survival or pulp healing.

There are some considerations in treatment of root fracture [15]. The first, the position of the coronal part after it has been fractured. Considering the position of the tooth first, the tooth fractured and displaced should be repositioned as soon as possible after the trauma, and if there is a mobility, it should be splinted with the adjacent teeth. The extent of healing is determined by the degree of luxation, but if only concussion occurs, the possibility of healing with calcified tissue is high, whereas displaced teeth are likely to heal with connective tissue.

The second consideration is the mobility of the coronal segment, which is related to the force applied to the tooth and the degree of bone support of the coronal segment. The splinting period is usually $8-10$ weeks.

Maintaining oral hygiene is also very important. This is because the gingival inflammation may cause the base of the gingival crevice to move to the apical region, causing the fracture line to communicate with the oral cavity, resulting in loss of the coronal fragment.

The third is the status of the pulp. If there is no pain or sinus tract, coronal pulp may be regarded as having viability, and revascularization and renervation of these damaged pulp will depend on the severity of the injury and the ability of the pulp to heal. If symptoms such as sinus tract appear, calcium hydroxide dressing is needed for large apical foramen of coronal segment during root canal treatment. Herforth and Strassburg [16] reported that a previously negative reaction on EPT can return to positive, usually within the first 2 months after injury. A period of at least 1 year can elapse before pulp excitability returns [17]. In second case, revascularization and renervation may have occurred.

The fourth, the location of fracture line also affects the prognosis of the root fractured tooth. The fracture line can be divided into three zones, of which the clinician can easily handle is apical third fracture. In this case, treatment may not be necessary. In case of coronal third fracture of root, the coronal fragment will be lost and prosthetic restoration will be needed after gingival contouring and endodontic treatment.

The most difficult location of fracture line to be treated by the clinician is the cervical $1 / 3$ fracture of root. If there is some movement of the gingival margins in the apical direction, there may be communication between the fragments and oral cavity. According to the Welbury et al. [18], the strongest indicator of tooth survival was the location of the root fracture and those with coronal or gingival third had the worst prognosis. In this case, periodontal surgery, forced eruption and surgical extrusion may be considered.

In the first case, the location of the fracture was in the middle 1/3 having a large amount of diastases and three grade mobility. Larger displacement of the coronal fragment due to re-trauma lead to complete rupture of the neurovascular bundle and the pulp exposed to oral environment. This resulted in pulp necrosis of the coronal fragment. In the follow-up $\mathrm{x}$-rays, the apical fragment showed no infectious symptoms and pulp obliteration was observed meaning pulp vitality is maintained. The healing pattern seems to be interposition of connective tissue or interposition of bone and connective tissue.

In the second case, although the location of the fracture is in the cervical $1 / 3$ which has the worst prognosis, there was less amount of diastases and mobility which resulted in vitality maintanence. According to the 8.6-year follow-up $\mathrm{x}$-rays, the healing pattern seems to be healing with calcified tissue. This case achieved successful healing without root canal therapy compared to the first case.

This report shows that teeth with fractured root were successfully treated without other pathological findings due to semi-rigid splinting with close reduction of the root segments and endodontic treatment. If the teeth can be repositioned, stabilized, and occlusally adjusted, the prognosis of a root-fractured tooth is quite favorable. Therefore, clinicians should be aware of the healing mechanism of 
root fracture.

In all traumatic injuries, early diagnosis and appropriate intervention dramatically enhance the outcome. The primary purpose of the treatment of root fractured teeth is to maintain the vitality of the teeth. After an adequate observation period, if vitality control reveals non-vital pulp tissue, or if the patient complains of pain or discomfort of the tooth, endodontic therapy can be performed, usually to the coronal segment only.

\section{ACKNOWLEDGEMENTS}

This study was supported by National Research Foundation of Korea (NRF) grant funded by the Korea government (MSIP) (No. 2016R1C1B1012703).

\section{CONFLICTS OF INTEREST}

The authors declare that they have no competing interests.

\section{ORCID}

\author{
Sung-Hyeon Choi \\ https://orcid.org/0000-0002-4324-6567 \\ Ji-Hye Yoon \\ https://orcid.org/0000-0003-2290-1128 \\ Bin-Na Lee \\ https://orcid.org/0000-0001-8017-1835 \\ Hoon-Sang Chang \\ https://orcid.org/0000-0002-3019-1528 \\ In-Nam Hwang \\ https://orcid.org/0000-0002-5388-1919 \\ Won-Mann Oh \\ https://orcid.org/0000-0001-6480-6191 \\ Yun-Chan Hwang \\ https://orcid.org/0000-0002-7891-9565
}

\section{REFERENCES}

1. Andreasen JO, Ravn JJ. Epidemiology of traumatic dental injuries to primary and permanent teeth in a Danish population sample. Int J Oral Surg 1972;1:235-239.
2. Skaare AB, Jacobsen I. Dental injuries in Norwegians aged 7-18 years. Dent Traumatol 2003;19:67-71.

3. Bastone EB, Freer TJ, McNamara JR. Epidemiology of dental trauma: a review of the literature. Aust Dent J 2000;45:2-9. doi: 10.1111/j.1834-7819.2000.tb00234.x.

4. Kusgoz A, Yildirim T, Tanriver M, Yesilyurt C. Treatment of horizontal root fractures using MTA as apical plug: report of 3 cases. Oral Surg Oral Med Oral Pathol Oral Radiol Endod 2009;107:e68-e72. doi: 10.1016/j.tripleo.2009.01.031.

5. Brandini DA, Poi WR, Panzarini SR, Sonoda CK, de Castro JC, Luvizuto ER, Leal CR. Integrated treatment to resolve a horizontal root fracture. Dent Traumatol 2009;25:e16-e20. doi: 10.1111/j.1600-9657.2008.00724.x.

6. Andreasen FM. Pulpal healing after luxation injuries and root fracture in the permanent dentition. Endod Dent Traumatol 1989;5:111-131.

7. Andreasen FM, Andreasen JO. Resorption and mineralization processes following root fracture of permanent incisors. Endod Dent Traumatol 1988;4:202-214.

8. Andreasen FM, Andreasen JO, Bayer T. Prognosis of rootfractured permanent incisors--prediction of healing modalities. Endod Dent Traumatol 1989;5:11-22.

9. Jacobsen I, Kerekes K. Diagnosis and treatment of pulp necrosis in permanent anterior teeth with root fracture. Scand J Dent Res 1980;88:370-376.

10. Flores MT, Andersson L, Andreasen JO, Bakland LK, Malmgren B, Barnett F, Bourguignon C, DiAngelis A, Hicks L, Sigurdsson A, Trope M, Tsukiboshi M, von Arx T; International Association of Dental Traumatology. Guidelines for the management of traumatic dental injuries. I. Fractures and luxations of permanent teeth. Dent Traumatol 2007;23:66-71. doi: 10.1111/j.1600-9657.2007.00592.x.

11. Andreasen JO, Hjorting-Hansen E. Intraalveolar root fractures: radiographic and histologic study of 50 cases. J Oral Surg 1967;25:414-426.

12. Versiani MA, de Sousa CJ, Cruz-Filho AM, Perez DE, SousaNeto MD. Clinical management and subsequent healing of teeth with horizontal root fractures. Dent Traumatol 2008;24:136-139. doi: 10.1111/j.1600-9657.2006.00507.x.

13. Andreasen JO, Andreasen FM, Mejàre I, Cvek M. Healing of 400 intra-alveolar root fractures. 2. Effect of treatment factors such as treatment delay, repositioning, splinting type and period and antibiotics. Dent Traumatol 2004;20:203211. doi: 10.1111/j.1600-9657.2004.00278.x.

14. Andreasen JO, Andreasen FM, Andersson L. Textbook and color atlas of traumatic injuries to the teeth. 4 th ed. Oxford: Blackwell Munksgaard; 2007;xiv-897.

15. Feiglin B. Clinical management of transverse root fractures. Dent Clin North Am 1995;39:53-78.

16. Herforth A, Strassburg M. [Therapy of chronic apical periodontitis in traumatically injuring front teeth with ongoing root growth]. Dtsch Zahnarztl Z 1977;32:453-459. German. 
17. Andreasen FM, Zhijie Y, Thomsen BL. Relationship between pulp dimensions and development of pulp necrosis after luxation injuries in the permanent dentition. Endod Dent Traumatol 1986;2:90-98.
18. Welbury R, Kinirons MJ, Day P, Humphreys K, Gregg TA. Outcomes for root-fractured permanent incisors: a retrospective study. Pediatr Dent 2002;24:98-102. 